Published in "Advances in Science and Technology Vol. 90 (2014) pp 12-18"

\title{
CHARACTERIZATION OF NANOSTRUCTURED PHASES AND PECULIAR PHASE TRANSITIONS IN BNBT LEAD-FREE PIEZOCERAMICS
}

\author{
L. Pardo ${ }^{1, a *}$, A. García ${ }^{1}$, K.Breb $\left.\emptyset\right|^{2}$, E. Mercadelli ${ }^{3}$ and C. Galassi ${ }^{3}$ \\ ${ }^{1}$ Instituto de Ciencia de Materiales de Madrid (ICMM) \\ Consejo Superior de Investigaciones Científicas (CSIC), Cantoblanco, 28049-Madrid, Spain \\ ${ }^{2}$ Limiel ApS. DK-4772, Langebæk, Denmark \\ ${ }^{3}$ National Research Council of Italy, Institute of Science and Technology for Ceramics \\ (CNR-ISTEC). Via Granarolo, 64. I-48018 Faenza (Italy) \\ Ipardo@icmm.csic.es \\ *corresponding author
}

Keywords: Bismuth Sodium Titanate; Barium Titanate; Lead-Free; Piezoelectric Ceramics; Ferroelectrics; Phase Transitions; Shear Resonances.

\begin{abstract}
Submicron-structured $\left(\mathrm{Bi}_{0.5} \mathrm{Na}_{0.5}\right)_{0.94} \mathrm{Ba}_{0.06} \mathrm{TiO}_{3}$ (BNBT6) dense ceramics, from nanometric powder synthesized by sol gel auto-combustion at $500^{\circ} \mathrm{C}$ and obtained by hot-pressing ( $800^{\circ} \mathrm{C}-2 \mathrm{~h}$ ) and subsequent recrystallization at moderate temperature (1000-1050ㄷ $-1 \mathrm{~h})$, have been studied. In-situ measurements at the shear mode of electromechanical resonance of non-standard thickness-poled shear plates as a function of the temperature show higher depolarization temperature than measurements at the radial mode of thin disks. Shear mode related material coefficients are measurable up to $160 \circ \mathrm{C}$, being $\mathrm{k}_{15} \approx 30 \%$ and $\mathrm{d}_{15} \approx 250 \mathrm{pC}$. $\mathrm{N}^{-1}$ at $130^{\circ} \mathrm{C}$.

Depolarization is a complex phenomena caused by a ferroelectric (FE) macrodomains thermal randomization and a phase transition from the field-induced FE phase to a relaxor phase. The early stage of such a transition involves a non-negligible piezoelectricity arising most probably by the percolative coexistence of ferroelectric macrodomains in the resonator under the given stress field for each resonance mode.
\end{abstract}

\section{Introduction}

The crystal structure and the electrical properties of $\mathrm{BaTiO}_{3}(\mathrm{BT})$, or $\mathrm{BiNaTiO}_{3}(\mathrm{BNT})$ have been studied from the 1950 decade and are now revisited, due to the strong need of development of high piezoelectric sensitivity and lead-free composition materials [1-4]. The wide Morphotropic Phase Boundary (MPB) in the solid solution system BNT-BT experiments an electric-field-induced phase transition from a nanostructured relaxor to a ferro-piezoelectric phase involving a crystal symmetry change $[4,5]$. Also, a phase transition underlies the thermal depolarization in these materials, taking place at $T_{d,}$, below the temperature of the ferro-paraelectric phase transition that determines the maximum of the dielectric permittivity [5]. Above $T_{d}$, a relaxor phase, a low 
temperature globally non-polar phase at zero field (LTNPZF), takes place. For compositions at the MPB of all BNT-based solid solutions [6], the relatively low thermal stability, since, typically, $100^{\circ} \mathrm{C}<\mathrm{T}_{d}<150^{\circ} \mathrm{C}$, is considered a drawback for practical applications. The measurement procedure of $T_{d}[7]$ and the exact structure of the LTNPZF phase are still a matter of discussion [3]. The depolarization of submicron-structured $\left(\mathrm{Bi}_{0.5} \mathrm{Na}_{0.5}\right)_{0.94} \mathrm{Ba}_{0.06} \mathrm{TiO}_{3}$ (BNBT6) ceramics at the MPB is here characterized by in-situ measurements of the thermal evolution of the electromechanical resonances of thin disks and shear plates, thickness poled, in order to seed light on these matters.

\section{Materials and Experimental methods}

Undoped (1-x) $\left(\mathrm{Bi}_{0.5} \mathrm{Na}_{0.5}\right) \mathrm{TiO}_{3}-\mathrm{xBaTiO}$ with $\mathrm{x}=0.06$ (BNBT6) nanometric $(15-30 \mathrm{~nm})$ powder was synthesized at $500 \circ \mathrm{C}$ by a citrate nitrate sol gel auto-combustion method [8]. Pellets of the powder of, typically, $15 \mathrm{~mm}$ diameter and $1 \mathrm{~mm}$ thickness were obtained by uniaxial pressure forming followed by cold isostatic pressing at $200 \mathrm{MPa}$. High density ( $\approx 96 \%$ theor. dens.), submicron structured $(\langle G\rangle \approx 600 \mathrm{~nm})$ were obtained by hot-pressing ( $800 \circ \mathrm{C}$ for $2 \mathrm{~h}$ ) and subsequent recrystallization (1000-1050ㄷ for $1 \mathrm{~h})$, as explained elsewhere [9], to reduce the loss of volatiles.

Sintered disks were ground to a thickness $(t)$ to diameter $(D)$ ratio below $1 / 20$ and were electroded. Rectangular plates of a lateral dimensions $(L, w)$ to thickness $(t)$ aspect ratio below $1 / 10$ (typically $\mathrm{t}=0.5$ and $\mathrm{L}, \mathrm{w}=5 \mathrm{~mm}$ ) were also cut from the sintered ceramic disks and electroded. Samples were thickness-poled at $150^{\circ} \mathrm{C}$ to saturation in a silicone oil bath for 30 minutes. Afterwards, they were cooled to room temperature with the electric field applied $\left(40 \mathrm{kV} . \mathrm{cm}^{-1}\right)$. Poling electrodes were mechanically removed from the plates and a new pair of electrodes was applied on perpendicular surfaces for the electric measurements.

Real part of the relative dielectric permittivity $\left(\varepsilon^{T^{\prime}{ }_{33}}\right)$ and losses (tan $\left.\delta\right)$ vs. temperature curves on heating and cooling runs were measured at various frequencies from impedance measurements in the range between $1 \mathrm{kHz}$ and $1 \mathrm{MHz}$ using a HP4194A analyzer.

Complex impedance measurements at radial resonance mode of disks and shear mode of thickness poled plates were also carried out with a HP4192A impedance analyzer in-situ as a function of the temperature on heating with a rate of $2 \stackrel{\circ}{\circ} / \mathrm{min}$ to study the thermal depoling of the samples. The evolution of the material coefficients corresponding to each mode was determined by analysis of the impedance curves at resonance using an iterative automatic method $[10,11]$. 


\section{Results and discussion}

Fig 1. shows the real part $\left(\varepsilon^{T^{\prime}}{ }_{33}\right)$ of the complex dielectric permittivity, $\varepsilon^{*^{T^{\prime}}}{ }_{33}$, and losses (tanס) vs. temperature curves of BNBT6 thin disks. As-sintered (Figs1(a,b)) and poled (Figs1(c,d)) samples were measured. The results on poled samples reveal a peak of tan $\delta$ and a sharp increase of $\varepsilon^{T^{\prime}{ }_{33}}$ from $T_{\mathrm{FE}-L T N P Z F} \approx 110 \circ \mathrm{C}$. The permittivity above $\mathrm{T}_{\mathrm{FE}-\mathrm{LTNPZF}}$ presents a high dispersion that extends to $\mathrm{T}_{\mathrm{i}} \approx 220^{\circ} \mathrm{C}$, the isotropization temperature [5], which is below the temperature of the maximum permittivity $\left(T_{m} \approx 280^{\circ} \mathrm{C}\right)$. Also, the permittivity exhibits a thermal hysteresis with the dispersive region extending on cooling to room temperature when measuring the thermally depoled sample (Fig. 1(d)). This behavior is in agreement with that previously found $[1,12]$.

The sharp increase of $\varepsilon^{T^{\prime}{ }_{33}}$ in poled samples is ascribed to the transition from the ferropiezoelectric phase (field-oriented ferroelectric macrodomains with long-range polar order) to a nanostructured dielectric relaxor phase (short-range polar order in nanodomains). In non-poled samples (Fig.1(a,b,d)) such a jump is not observed. The lack of a sharp decrease of $\varepsilon^{T^{\prime}{ }_{33}}$ on cooling the samples is ascribed to absence of the same nanodomain-macrodomain transition, that only takes place in the presence of an electric field.

The thermal evolution of the in-situ measured electric impedance of thin disks at the radial resonance mode is shown in Fig. 2. Instead of the commonly used modulus (IZI) and phase $(\theta)$ plots for the complex impedance as a function of the frequency, an alternative representation of the resonance spectra was used here. Namely, the resistance $(R=|Z| \cdot \cos \theta)$ and conductance $\left(G=|Z|^{-1} \cdot \cos \theta\right)$ peaks were plot as a function of the temperature. Depolarization temperatures are currently measured using this mode [7] that, nevertheless, is the mode with the lowest electromechanical coupling factor in these materials [6].

Similarly, Fig. 3(a) and (b) shows the plots of the resistance and conductance for the shear resonance mode of plates as a function of the temperature. Only the region above the temperature of the dielectric anomaly (Fig.1(c)) is shown in Fig.3. Fig. 3(c) shows an example of a reliable calculation of the material parameters at $130^{\circ} \mathrm{C}$. The reproduced spectrum (lines), using the calculated parameters [10], to the experimental spectrum (symbols) regression factor is $\mathrm{R}^{2}=0.9627$.

In-situ measurements of the radial resonance mode during the thermal depolarization process of BNBT6 ceramic disks (Fig. 2), and all the coefficients that can be directly calculated from it (Fig. 4), shows that for $125^{\circ} \mathrm{C}$ the resonance completely vanished, as previously reported. However, it can be seen that the complex impedance signal for the shear resonance of nonstandard thickness poled shear plates (Fig. 3), and all the coefficients that can be directly obtained 
from it (Fig. 4), decreases at higher temperature than that of the resonances of disks. At $130^{\circ} \mathrm{C}$, a shear coupling factor of $78 \%$ of the room temperature value $\left(\mathrm{k}^{\mathrm{RT}}{ }_{15}=40.4 \%\right)$ and piezoelectric coefficient of $167 \%$ of such a value $\left(d^{R T}{ }_{15}=158 \mathrm{pC} / \mathrm{N}\right)$ were calculated. The $\mathrm{G}$ and $\mathrm{R}$ curves for the shear mode shows also clear signal from which parameters can be calculated up to 160 으 (Fig. 4) and a residual signal can be found even above $250^{\circ} \mathrm{C}$ (Fig. 3(d)).

We can conclude that the thermal depolarization temperature of BNBT6, $T_{d}$, as measured in-situ from shear resonance mode of thin plates as a function of the temperature is above the one determined from in-situ measurements of the planar resonance mode of thin disks. This anisotropic electromechanical response has been repeatedly observed for submicron-structured and dense ceramics obtained by hot-pressing and subsequent recrystallization, both for BNBT4 $[13,14]$ and BNBT6 compositions [5]. In particular, the thermal depolarization of BNBT6 is a complex process [5], involving both progressive reduction of the preferential orientation of the macrodomains of the ferro-piezoelectric phase and a structural phase transition to a relaxor, nanostructured phase, and it is irreversible, hence the dielectric hysteresis (Fig. 1). This ferroelectric to relaxor transition seems to be a point of metastability and has been found at higher temperature when measured under electric field or under stress [15]. Our measurements in disks and shear plates of the dielectric permittivity at resonance (Fig.4(e)) [10,11] and the low signal dielectric permittivity (Fig. 1(c) and Fig.4(f)), $\varepsilon^{T^{\prime}{ }_{33}}$ and $\varepsilon^{T^{\prime}{ }_{11}}$, seem to confirm this discrepancies in the measurement of the phase transition temperature in parallel and perpendicular directions to the poling field, respectively.

The electromechanical anisotropy, which we have found at in-situ measurements of the resonance in this and previous works $[5,13,14]$ for these materials, maybe enhanced by a favorable crystallographic preferential orientation [2,3] induced by the hot-pressing procedure. However, it most probably arises from the different stress field at each specific electromechanical resonance, according to our results, higher at the shear mode than at the radial one, which affects the in-situ measured depolarization temperature. The early stage of such a time dependent [14] transition to the LTNPZF phase involves a non-negligible piezoelectricity caused by the percolative coexistence of ferroelectric macrodomains, extending the working temperature of these materials in shear mode.

Acknowledgements. This work was funded by Spanish CSIC project \#201060E069. LP and AG wish to thank Mr. José Luis Millán (FINNOVA 2010 grantee) for his technical assistance in the quantitative microstructural characterization. 


\section{Literature References}

[1] B. Wylie-van Eerd, D.Damjanovic, N. Klein, N. Setter and J.Trodahl. "Structural complexity of $\left(\mathrm{Na}_{0.5} \mathrm{Bi}_{0.5}\right) \mathrm{TiO}_{3}-\mathrm{BaTiO}_{3}$ as revealed by Raman spectroscopy" Physical Review B, 82 (2010) 104112 [2] L. E. Fuentes-Cobas, L. Pardo, M. E. Montero-Cabrera, J. R. Plaisier, A. García, K. Brebøl, E. Mercadelli and C. Galassi. "The 0.96 $\left(\mathrm{Bi}_{0.5} \mathrm{Na}_{0.5}\right) \mathrm{TiO}_{3}-0.04 \mathrm{BaTiO}_{3}$ crystal structure: A high-Q, highcounting statistics synchrotron diffraction analysis" Crystal Research and Technology 49 (2-3) (2014) 190-194 .

[3] M. E. Montero-Cabrera, L. Pardo, A. García, M. E. Fuentes-Montero, M. L. Ballinas-Casarrubias and L.E. Fuentes-Cobas. "The global and local symmetries of nanostructured ferroelectric relaxor $0.94\left(\mathrm{Bi}_{0.5} \mathrm{Na}_{0.5}\right) \mathrm{TiO}_{3}-0.06 \mathrm{BaTiO}_{3}$ " Ferroelectrics (in press, 2014).

[4] W. Jo, J.E. Daniels, J.L. Jones, X. Tan, P. Thomas, D. Damjanovic and J. Rödel "Evolving morphotropic phase boundary in lead-free $\left(\mathrm{Bi}_{1 / 2} \mathrm{Na}_{1 / 2}\right) \mathrm{TiO}_{3}-\mathrm{BaTiO}_{3}$ piezoceramics" J. Appl. Phys. 109 (2011) 014110

[5] L. Pardo, E. Mercadelli, A. García, K. Breb $\varnothing$ l and C. Galassi. "Field-Induced Phase Transition and Relaxor Character in Submicron Structured Lead-Free $\left(\mathrm{Bi}_{0.5} \mathrm{Na}_{0.5}\right)_{0.94} \mathrm{Ba}_{0.06} \mathrm{TiO}_{3}$ Piezoceramics at the Morphotropic Phase Boundary" IEEE Trans Ultrasonics Ferroelectrics and Frequency Control 58(9) (2011) 1893-1904

[6] T.Takenaka, H. Nagata and Y. Hiruma "Phase Transition Temperatures and Piezoelectric Properties of $\left(\mathrm{Bi}_{1 / 2} \mathrm{Na}_{1 / 2}\right) \mathrm{TiO}_{3}$ - and $\left(\mathrm{Bi}_{1 / 2} \mathrm{~K}_{1 / 2}\right) \mathrm{TiO}_{3}$-Based Bismuth Perovskite Lead-Free Ferroelectric Ceramics" IEEE Trans. Ultrasonics, Ferroelectrics and Frequency Control 56(8) (2009) 1595-1612. [7] E.M. Anton, W. Jo, D. Damjanovic and J. Rödel "Determination of depolarization temperature of $\mathrm{Bi}_{1 / 2} \mathrm{Na}_{1 / 2} \mathrm{TiO}_{3}$-based lead-free piezoeceramics" J.Appl. Phys. 110 (2011) 094108

[8] E. Mercadelli, C. Galassi, A.L. Costa, S.Albonetti and A. Sanson. "Sol-gel combustion synthesis of BNBT powders” J. Sol-Gel Sci. and Technol. , 46(1) (2008) 39

[9] L. Pardo, E. Mercadelli, K. Brebøl, A. García and C. Galassi. "Piezoelectric properties of lead-free submicron structured $\left(\mathrm{Bi}_{0.5} \mathrm{Na}_{0.5}\right)_{0.94} \mathrm{Ba}_{0.06} \mathrm{TiO}_{3}$ ceramics" Smart Materials and Structures $19(11)$ (2010) 1507

[10] C. Alemany, A. M. Gónzalez, L. Pardo, B. Jiménez, F. Carmona, J. Mendiola "Automatic determination of complex constants of piezoelectric lossy materials in the radial mode" J. Phys. D: Appl. Phys. 28 (1995) 945-956

[11] L. Pardo, A. García, F. Montero de Espinosa and K. Brebøl. "Shear Resonance Mode Decoupling to Determine the Characteristic Matrix of Piezoceramics for 3-D Modelling." IEEE Trans. Ultrasonics Ferroelectrics and Frequency Control 58 (3) (2011) 646-657

[12] F. Cracium, C. Galassi and R. Birjega "Electric-field-induced and spontaneous relaxorferroelectric phase transitions in $\left(\mathrm{Na}_{1 / 2} \mathrm{Bi}_{1 / 2}\right)_{1-x} \mathrm{Ba}_{x} \mathrm{TiO}_{3}$ "J.Appl.Phys. 112 (2012) 124106

[13] L. Pardo, A. García, K. Brebøl, E. Mercadelli and C. Galassi. "Enhanced properties for ultrasonic transduction, phase transitions and thermal depoling in $0.96\left(\mathrm{Bi}_{0.5} \mathrm{Na}_{0.5}\right) \mathrm{TiO}_{3}-0.04 \mathrm{BaTiO}_{3}$ submicron structured ceramic". J. Phys. D: Appl. Phys. 44 (2011) 335404

[14] L. Pardo, A. García, K. Brebøl, E. Mercadeli and C. Galassi. "Anisotropy and dynamic thermal depolarization of $0.96\left(\mathrm{Bi}_{0.5} \mathrm{Na}_{0.5}\right) \mathrm{TiO}_{3}-0.04 \mathrm{BaTiO}_{3}$ lead- free piezoceramics" Book Series: IEEE International Symposium on Applications of Ferroelectrics (2012) Digital Object Identifier: 10.1109/ISAF.2012.6297762

[15] R. Dittmer, K.G. Webber, E. Aulbach, W. Jo, X. Tan and J. Rodel. "Electric-field induced polarization and strain in $0.94\left(\mathrm{Bi}_{1 / 2} \mathrm{Na}_{1 / 2}\right) \mathrm{TiO}_{3}-0.06 \mathrm{BaTiO}_{3}$ under uniaxial stress" Acta Mat. 61 (2013) 1350-1358 


\section{Figure captions}

Figure 1. Real part of the dielectric permittivity, $\varepsilon^{\prime}$, and losses, $\tan \delta$, for (a) heating and (b) cooling measurement runs of an as-sintered sample and for measurements of a poled sample (c) on heating, $\varepsilon^{T^{\prime}{ }_{33}}$, and (d) on cooling. Arrows indicate heating and cooling runs and increasing frequency.

Figure 2. Thermal evolution of the complex impedance at the RADIAL mode resonance of a BNBT6 thin disk, thickness poled: (a) conductance $(G)$ and $(b)$ resistance $(R)$ peaks.

Figure 3. Thermal evolution of the complex impedance at the SHEAR mode resonance of BNBT6 shear plates, thickness poled, at temperatures above that of the low temperature dielectric anomaly: (a) conductance $(G)$ and (b) resistance (R) peaks. (c) Experimental spectrum (symbols) and reproduced spectrum(lines) by the iterative method [12] at $130^{\circ} \mathrm{C}$. (d) Residual spectrum at $273^{\circ} \mathrm{C}$.

Figure 4. Comparison of the parameters from the in-situ measurements of RADIAL and SHEAR modes of resonance: $(a)$ series $\left(f_{s}-\right.$ from $\left.G_{\max }\right)$ and parallel $\left(f_{p}\right.$-from $\left.R_{\max }\right)$ frequencies; $(b)$ electromechanical coupling coefficients; (c) real part of the complex elastic compliances; (d) real part of the $d_{i j}$ coefficients; (d) real part of the complex dielectric permittivity at the resonance frequency; (e) real part of the low signal dielectric permittivity. 
(a)

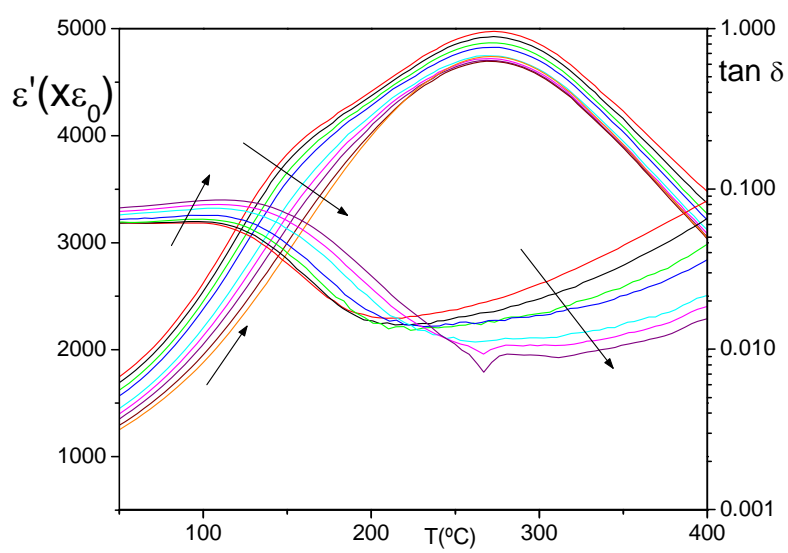

(c)

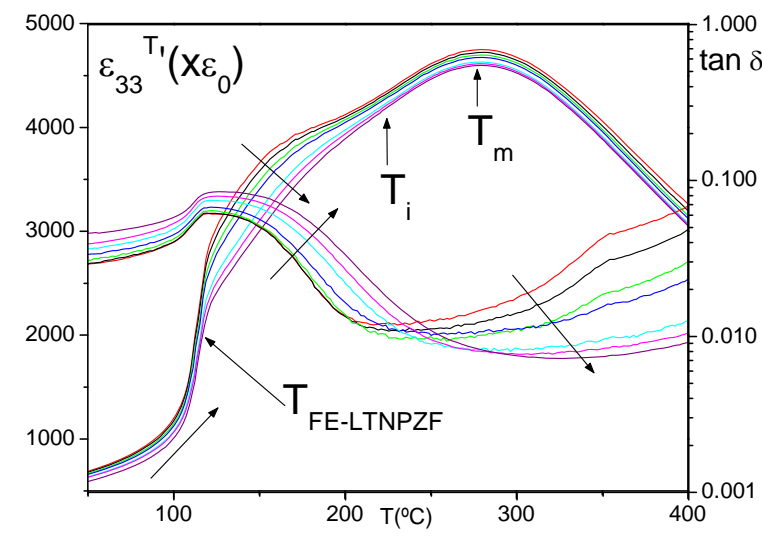

(b)

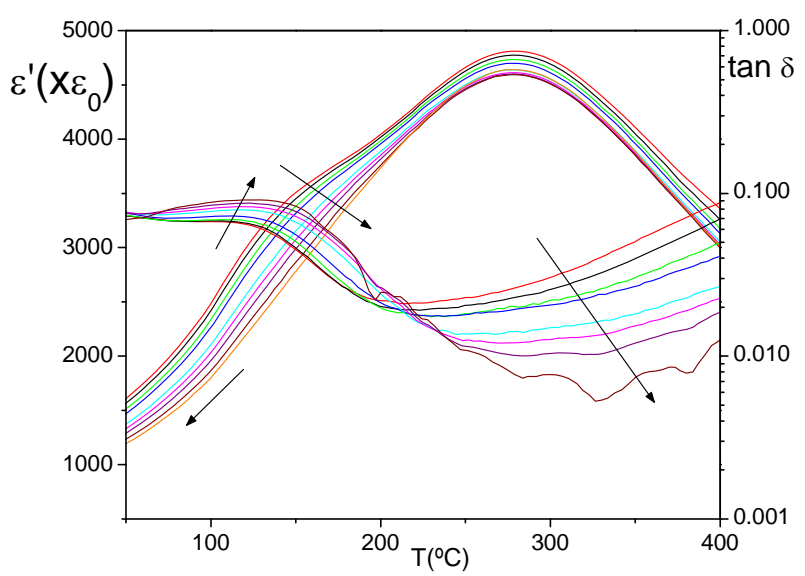

(d)

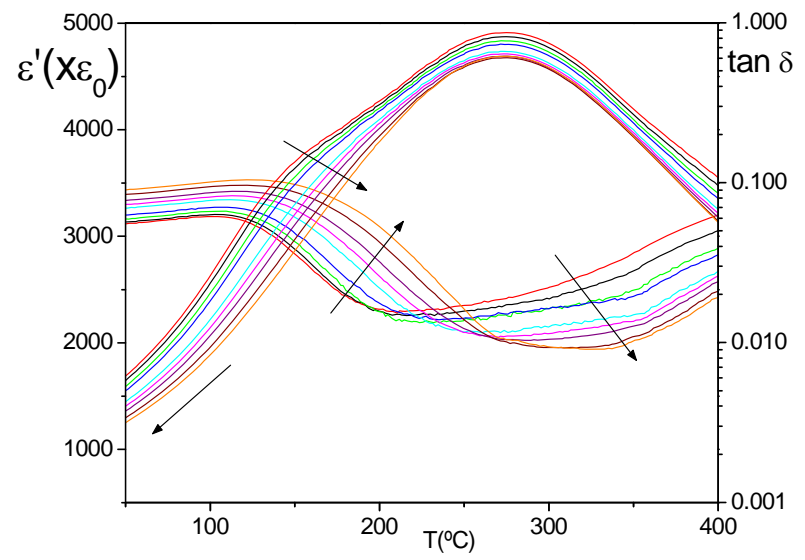

Fig.1/4 in "Characterization of nanostructured phases..." by L. Pardo et al. 
(a)

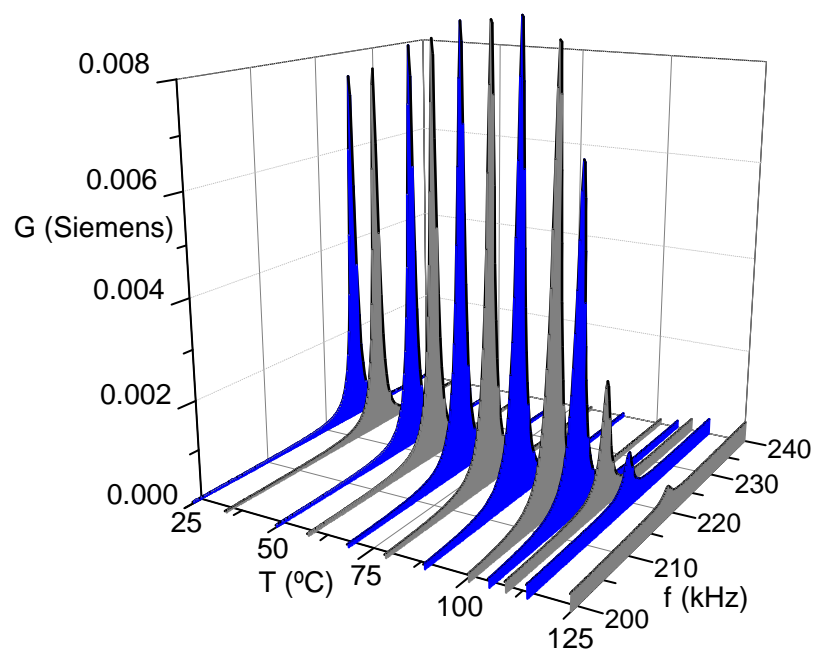

(b)

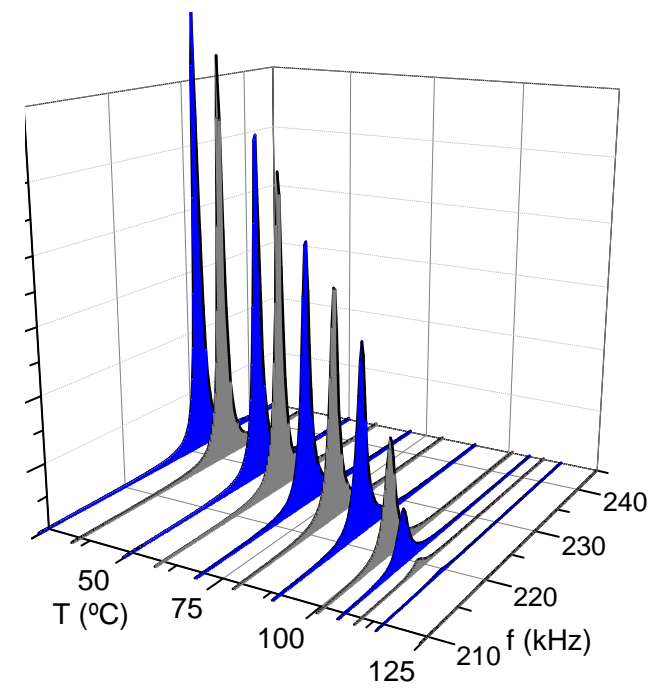

Fig.2/4 in "Characterization of nanostructured phases..." by L. Pardo et al. 
(a)

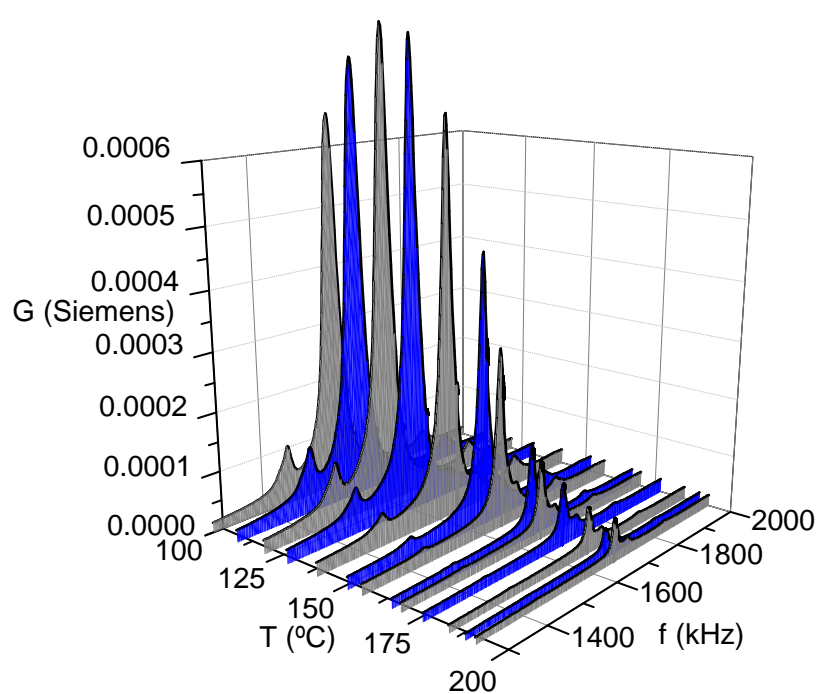

(c)

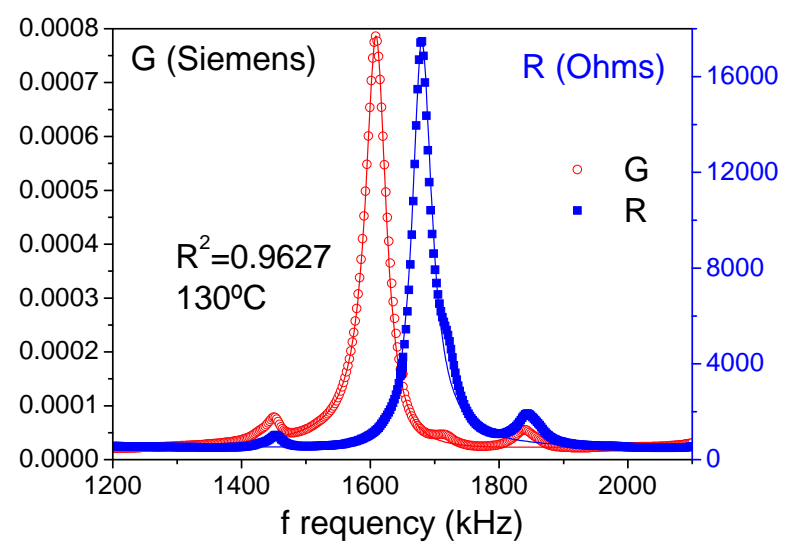

(b)

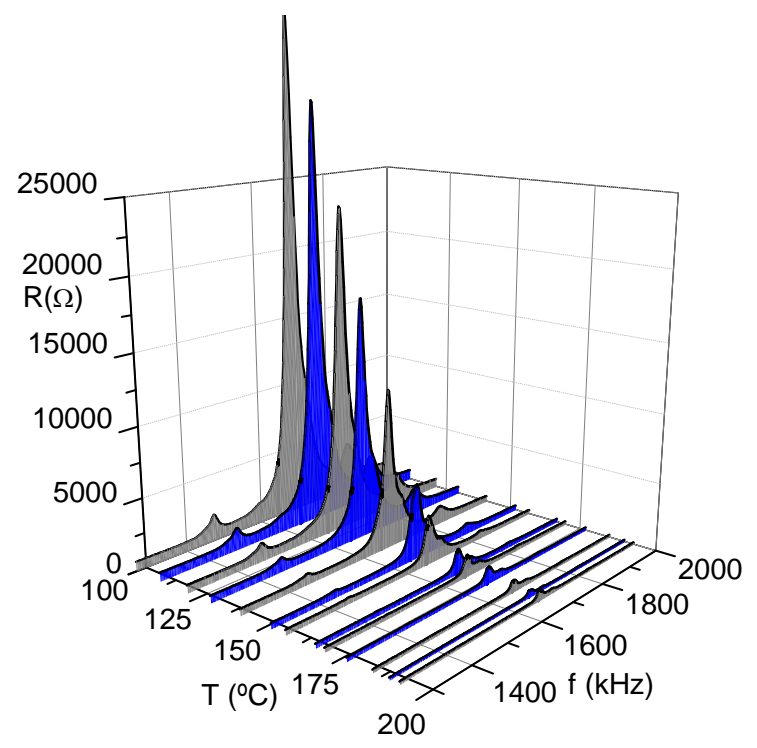

(d)

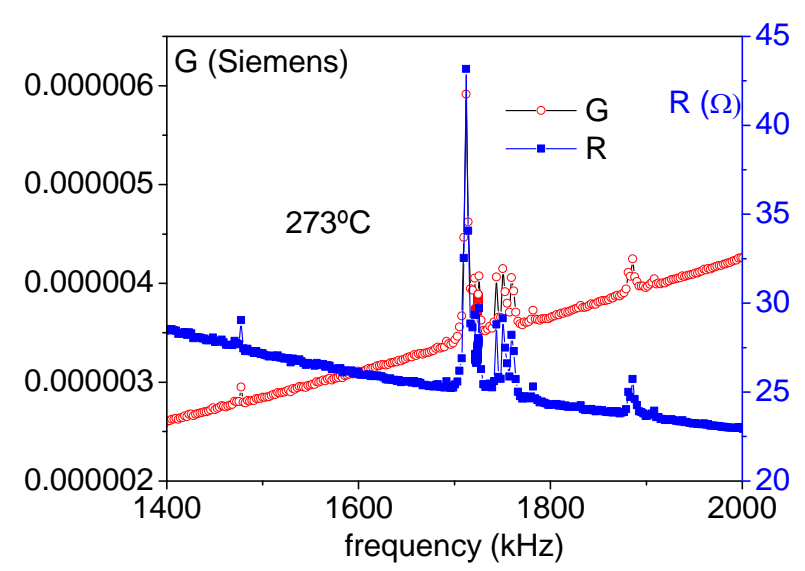

Fig.3/4 in "Characterization of nanostructured phases..." by L. Pardo et al.. 
(a)

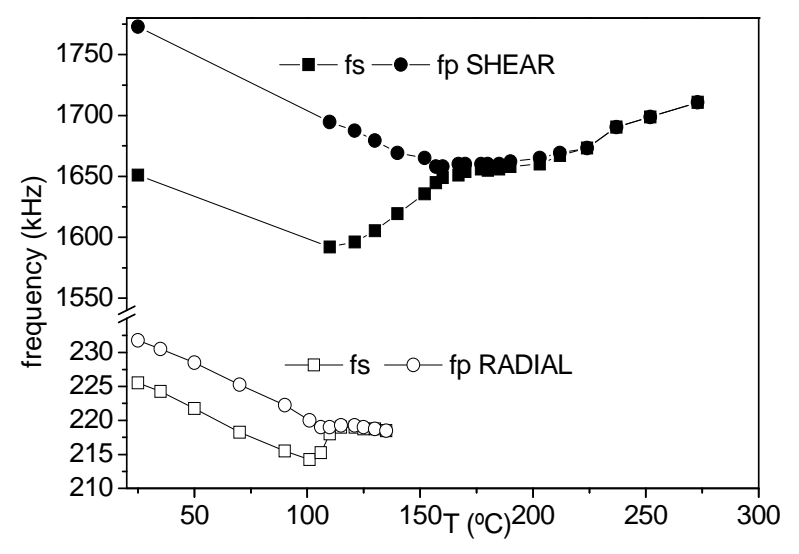

(c)

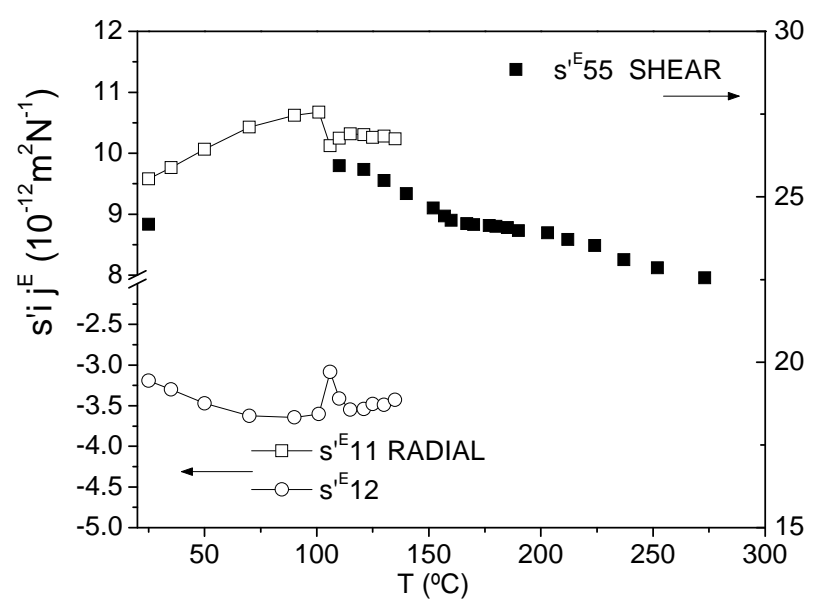

(e)

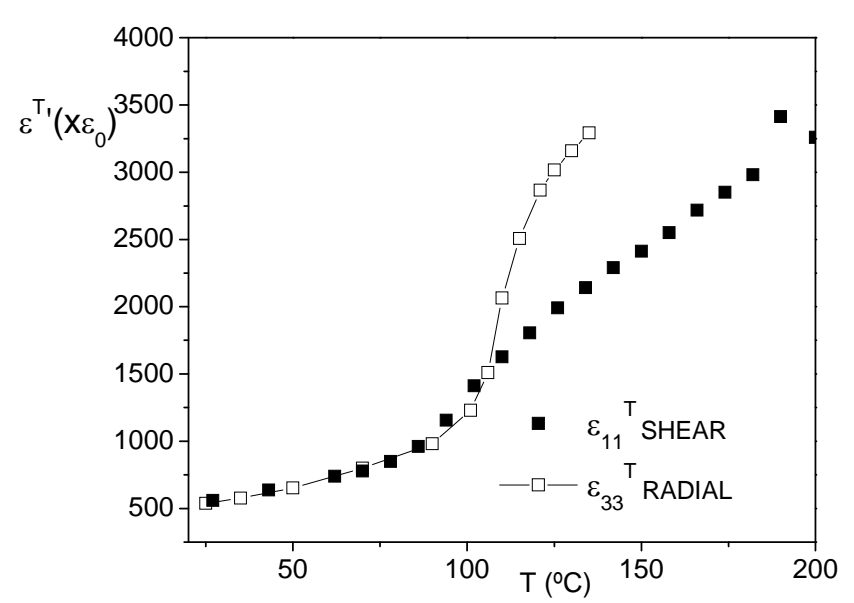

(b)

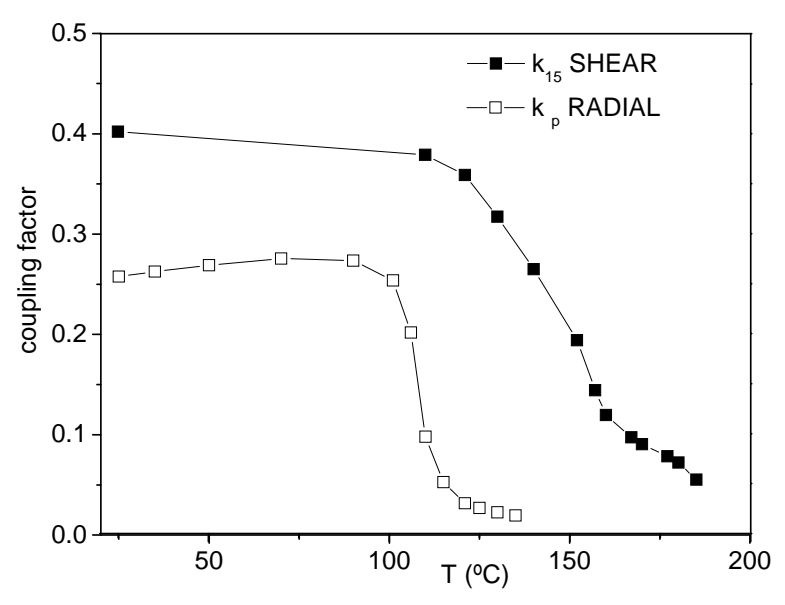

(d)

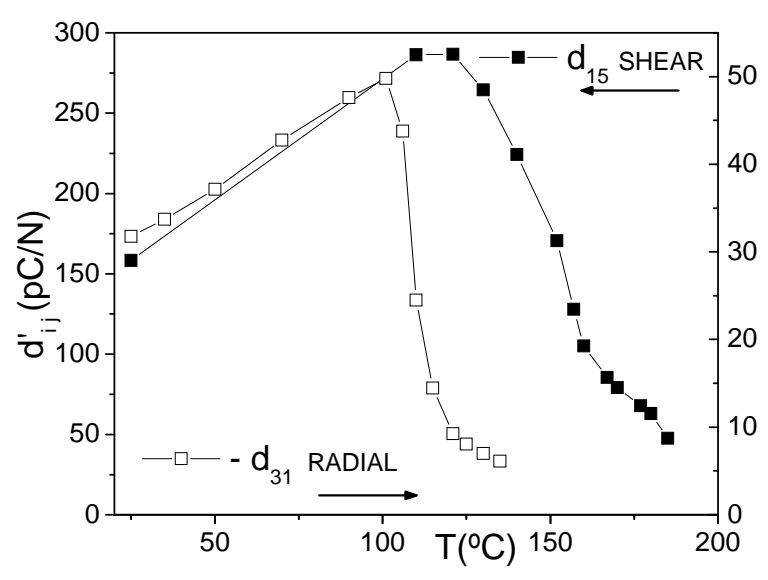

(f)

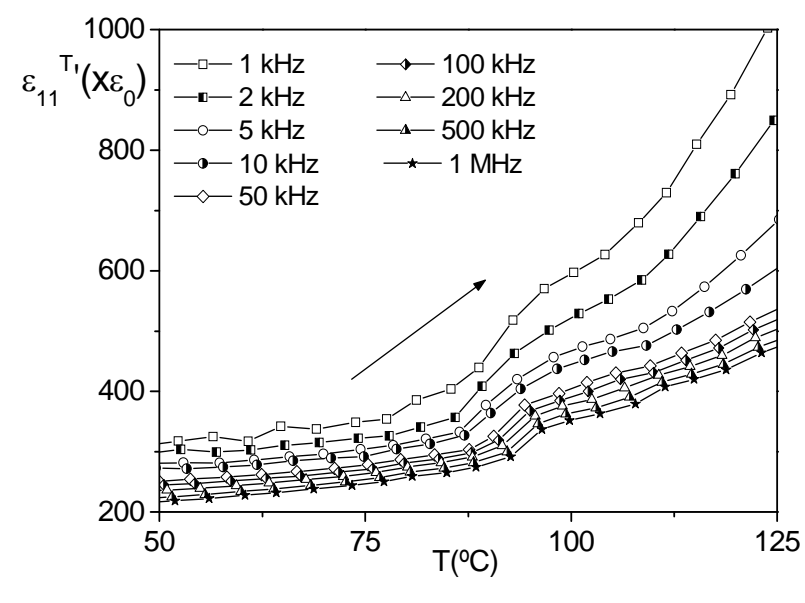

Fig. 4/4 in "Characterization of nanostructured phases..." by L. Pardo et al. 